\title{
Implications of Grassroots Sustainable Agriculture Community Values on the Design of Information Systems
}

JULIET NORTON, University of California, Irvine, USA and North Carolina State University, Raleigh, NC, USA

BIRGIT PENZENSTADLER, Chalmers University of Technology, Gothenburg, Sweden, California State University, Long Beach, USA, and Lappeenranta University of Technology, Finland

BILL TOMLINSON, University of California, Irvine, USA and Victoria University of Wellington, New Zealand

Information system designers embed values into the systems they design, even if unwittingly. However, the values embedded in many information systems clash with values held by many sustainability communities. This research focuses on two grassroots sustainable agriculture communities, which are seeking to develop a food infrastructure that is under their own control, and thereby more resilient to disruptions across the globe. This paper presents a five-year ethnographic study of these two communities, maps out the values of members of these communities, and explores the implications of their values on the information systems that members use and that could be developed to support them in the future. By doing so, we hope to influence the design of future information systems to align more closely with the values of these stakeholders, and through these stakeholders to move toward a food system that supports food security and global sustainability.

CCS Concepts: • Human-centered computing $\rightarrow$ HCI theory, concepts and models; Empirical studies in HCI;

Additional Key Words and Phrases: permaculture, sustainability, agriculture, values, information systems, HCI, limits

\section{ACM Reference format:}

Juliet Norton, Birgit Penzenstadler, and Bill Tomlinson. 2019. Implications of Grassroots Sustainable Agriculture Community Values on the Design of Information Systems. Proc. ACM Hum.-Comput. Interact. 3, CSCW, Article 34 (November 2019), 22 pages.

https://doi.org/10.1145/3359136

\section{INTRODUCTION}

Permaculture is a social movement and design ideology that applies the concept of structural and functional permanence to agriculture (i.e., permanent + agriculture = permaculture). Permaculture founder Bill Mollison first described permaculture as "an ecological design practice that aims to integrate landscape and people to provide for their own food, energy, shelter, and other material and non-material needs in a sustainable way" [54, p. xi]. In the three decades since then, permaculture has explored the social and ecological systems necessary for sustainable human settlements such as alternative economic systems and inter-plant interactions.

Permission to make digital or hard copies of all or part of this work for personal or classroom use is granted without fee provided that copies are not made or distributed for profit or commercial advantage and that copies bear this notice and the full citation on the first page. Copyrights for components of this work owned by others than the author(s) must be honored. Abstracting with credit is permitted. To copy otherwise, or republish, to post on servers or to redistribute to lists, requires prior specific permission and/or a fee. Request permissions from permissions@acm.org.

(C) 2019 Copyright held by the owner/author(s). Publication rights licensed to Association for Computing Machinery.

2573-0142/2019/11-ART34 \$15.00

https://doi.org/10.1145/3359136

Proc. ACM Hum.-Comput. Interact., Vol. 3, No. CSCW, Article 34. Publication date: November 2019. 


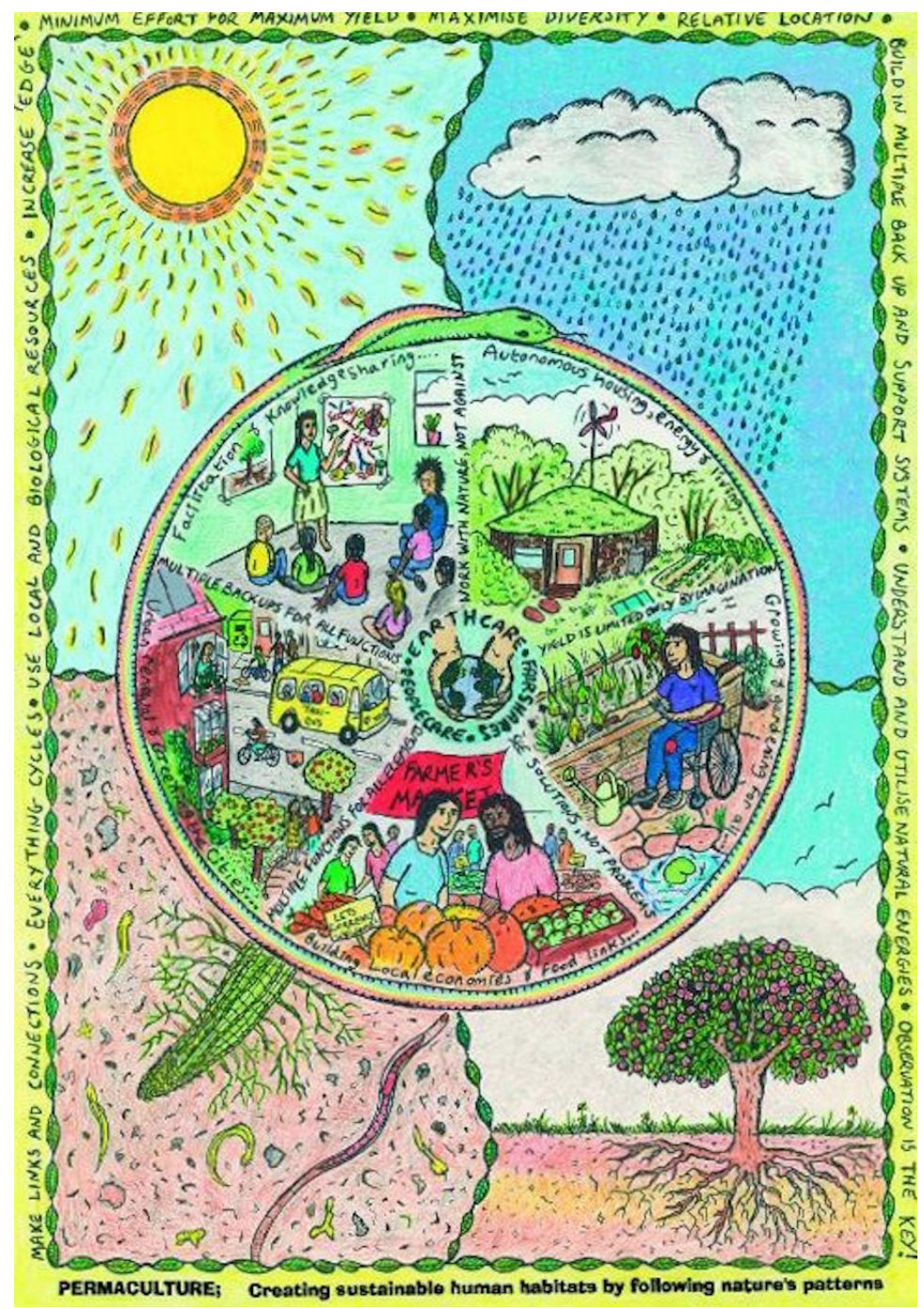

Fig. 1. Permaculture Mandala by Burnett [14] depicting potential manifestations of permaculture values.

At the foundation of permaculture methods are core ethics and principles for a "conscious" design practice [37, 54, 55]. Conscious design denotes the intention of designing for self-reliance and functionality of the all-encompassing (i.e., human and other natural) ecosystem. The core ethics and principles have significant social implications for participants who structure their identities, work, and personal lives around them, including their information technology use practices.

Permaculture pictorials and narratives have a shared theme of coupled human and natural systems in which agriculture functions. A popular permaculture mandala (Fig. 1) depicts a ring of systems centered around or supporting human activity, lush with productive foliage and food, set within the natural environment to emphasize that human systems are a part of the natural environment. The shown human-supporting systems mimic nature and attempt to include technologies that are not resource-intensive. An "autonomous" home has a green roof, a small wind turbine, a 
small solar array, and a rain barrel. A classroom of children is small and personal, with multiple instructors for few children, and features ecological educational content. A green cityscape has people commuting by bus and bicycle but not by car. On the street there are recycling centers, window and green-space gardens, and solar panels on roofs. A farmer's market is shown as a place for a thriving local economy, where farmers and patrons of many cultures gather and buy or sell fresh local food and products. A community garden has a gardener in a wheelchair working at a raised bed, demonstrating the importance of creating community facilities services that are accessible to everyone's needs. This mandala reflects a subset of the community values present in permaculture.

The core permaculture ethics are: earth care, fair share, and people care [37]. Between the coupled natural and human systems in Fig. 1, around the coupled systems ring, and framing the extended natural systems, are core principles that drive the permaculture design of sustainable agriculture, including: everything cycles; use local and biological resources; maximize diversity; build in multiple back up and support systems; work with nature, not against it; and enable multiple functions for all elements.

The goal of the research presented in this paper is to understand and explore the implications of grassroots sustainable agriculture community values on the design of information technology. The first author conducted a five year qualitative study with two permaculture communities in the United States. As an observing participant, the first author mapped out the communities' values from the perspective of a member.

This research argues that the values of these two permaculture communities, which are heavily influenced by the core permaculture-movement ethics and values, profoundly affect the kinds of information technology these communities are willing to use and that can effectively support their practices. More broadly, we argue that these constraints have the potential to help technologists address the unsustainability of sociotechnical complexity, which are defined as prolonged periods of diminishing returns to complexity by Tainter [84].

The next section of this paper introduces the related work in computing relevant to human values, sustainability, and agriculture. Section three, the research context, introduces the two permaculture communities that participated in this research and summarizes the research methods for this work. Section four, Permaculture Community Values, provides a summary of the values embedded in the two permaculture communities. In section five we discuss the implications of these values for information technology design in the context of sociotechnical complexity.

\section{RELATED WORK}

The next section positions this study in relation to previous scholarly work in three related domains: the role of values in the design of information technology; how the value of sustainability has impacted the $\mathrm{HCI} / \mathrm{CSCW}$ space; and how food and agriculture have been a growing locus for work at the juncture of values, sustainability, and technology. We then describe how this paper presents new insights into the ways in which the values of a community with an uncommon relationship to technology (for example, a reluctance to become dependent on it), can be used to design systems that support these communities while still respecting their values. This research seeks to inform both existing work at the juncture of sustainability and $\mathrm{HCI} / \mathrm{CSCW}$, as well as other contexts in which communities hold ambivalent relationships to technology.

\subsection{Values in the Design of Information Technology}

Twenty years ago, Bowker and Star asserted that information systems researchers need to realize that all information systems are imbued with ethical and political values [12]. Designers imbue their technologies with values and social agendas, even if unintentionally [56]. When users' values

Proc. ACM Hum.-Comput. Interact., Vol. 3, No. CSCW, Article 34. Publication date: November 2019. 
and social agendas differ from those embedded in the technology, users may experience "reverse adaptation" [95, p. 229]. Reverse adaptation occurs when users adjust their process and conform to the values embedded in the information systems they use. Avoiding reverse adaptation and intentionally supporting human values with ethical importance, HCI researchers spearheaded the exploration into value sensitive design (VSD) methods [24]. In the time since, HCI researchers have explored how the value of sustainability take shape in and are shaped by IT [7, 30, 51, 72]. Our work seeks to inform the design of IT in ways that are highly sensitive to the community's values by providing a perspective informed by a sustainability community (the permaculture community) with strongly ambivalent values surrounding technology itself. For this study, a "value" is defined as something that a person or a community thinks is important. We use this broad definition of value in effort to also encompass the concepts of ethics and principles because participants often used these three terms synonymously.

VSD, as developed by Friedman, Kahn, and Borning [24] and extended by other researchers $[11,22,43]$, highlights the need for incorporating individual and/or community values into the process of designing information systems. VSD involves identifying the harms and benefits for each stakeholder group of a designed technology, mapping those harms and benefits to moral values, and integrating those value considerations into the design. Our research investigated the harms, benefits, and moral values of the stakeholders so they can be incorporated into the design of information technologies for the participating communities.

\subsection{Sustainability in $\mathrm{HCl}$}

DiSalvo, Sengers, and Brynjarsdóttir [17] first "mapped the landscape" of S-HCI into genres of similar problems or ways of addressing problems and asserted that the field of S-HCI needed to use the knowledge of existing S-HCI research as the basis for discovering and addressing new problems including collective and regional contexts, finding ways other than moral conscience to engage users, and helping users become experts on sustainability on their own terms. In context of their mapping [17], this research falls under "formative user studies" genre and explores problems in local, collective contexts. This work is adapted from and builds on qualitative research techniques used by previous formative user studies within S-HCI to report on and champion special consideration of practices by people who lead alternative sustainability life styles $[8,28,58,90]$ and people who grow food [3, 10, 44, 48, 63, 93]. Our work extends this area of research by engaging in observant participation, a qualitative research method that anthropologist João H. Costa Vargas [92] differentiates from the traditional participant observation to underline the importance of participation rather than observation. In focusing on participation in the community and engagement with the community members, an overwhelming amount of the observation data came from informal, and at times unexpected, interactions.

Knowles et al. [41] followed up the first mapping with a different systematic mapping method in 2013, asserting that existing S-HCI research is premised in the Triple-Bottom Line framing of sustainability, and argues for radical "designing for sustainability," which sets aside the assumption of continuance of the way life currently is. In context of their mapping [41], this research informs our next steps in "designing for sustainability," as we work towards designing information ecologies that support communities that are radically re-imagining and building sustainable human civilizations. To do so, this work draws on previous efforts to design for sustainability such as the design of technologies that support the work of farmers and gardeners [31, 35, 50, 80], citizen science for gathering data necessary for sustainability initiatives $[68,94]$, using a crowd for participation in sustainable behavior [52, 76], and sustainable interaction design [7, 20, 69]. Our work extends this previous research by demonstrating the importance of understanding and addressing the particular 
values held by the community for whom one is designing, both in the sustainability domain and with other values as well.

Collapse informatics, adaptation informatics, and computing within limits are complementary research domains that explore the shortfalls of the mostly mitigation-focused approach of S-HCI. Collapse informatics is the "study, design, and development of sociotechnical systems in the abundant present for use in a future of scarcity" [86]. Collapse informatics is motivated by the concept of societal collapse, which Tainter [83] defined as a rapid decrease in established societal complexity. Adaptation informatics examines the role of information systems in futures where mitigation of the effects of environmental change may not be possible [89]. Computing within limits is a relatively new area of research that explores the limits of computing in the context of ecology, materiality, and energy [57]. A range of different topics from these domains resonate with ideas commonly found within permaculture communities, including the rapid obsolescence of technology [39,73, 87], communities adapting to resource scarcity [27, 66, 67], and preparing modern systems and infrastructures for long-term use [25, 81]. Because these three related domains are well aligned with the worldview of many members of the permaculture communities studied in this paper, the work described here builds on the approaches to computing described in these domains. While the primary contribution of this paper focuses on the relationship between information systems and permaculture/grassroots sustainable agriculture, the work presented here is relevant to these other sociotechnical contexts characterized by scarcity and disruption as well.

\subsection{Food and Agriculture in $\mathrm{HCl}$}

The research described here crosses boundaries between computing and farming, food, and sustainability activism. Food-CHI has some overlap with Sustainable-HCI, such as in the context of those exploring and designing components of or entire sustainable food systems, e.g., [36, 42, 60, 62]. The subset of the sustainable food-centered research in HCI that focuses on supporting people who grow food demonstrates the unique sets of values food growers maintain in their practice, the translation of those values into the information technologies appropriate, and the challenges of maintaining those values in the technologies we design for food growers.

Some HCI research has demonstrated the transference and translation of food growers' practice values to their information practices. For example, one organic food community valued local sustainable food production, community collaboration, and knowledge sharing and appropriated technologies that demonstrated values of transparency, collaboration, and professionalism to support their core volunteer work [10].

However, sometimes those values did not transfer to information practices. The information practices of two ecovillages did not reflect their daily-life sustainability practices; it turned out the use of information tools continued to be unsustainable (e.g. burden of emails) and members voiced frustration about not finding better alternatives than the "tyranny of the norm" [59, p. 2264]. HCI and $\mathrm{CSCW}$ research also demonstrated that food-growers have unique requirements for information systems that support their work. For example, small-scale organic farming families uniquely merge their work and home life, yielding unique values for technological support including supporting the natural rhythms of family life, unmediated face-to-face interaction, being outside, and a person's ability to multi-class in their roles [44]. For another example, a collection of small mid-western farmers working to form a local food network had a value set characterized by balance require information systems that support selective transparency, socialization of newcomers with seasoned farmers, and the equity of disadvantaged newcomers [82].

$\mathrm{HCI}$ researchers have also identified design challenges and values tensions when exploring the complexities of the greater food system context that food growers operate within. For example, a local food network made up of a wide representation of food system stakeholders (from production 
to waste) faced tensions between their values of food democracy and affordability and would benefit from research into technologies that question the neoliberal market economics underlying those tensions [70]. Interestingly, such challenges exist even when designing information systems for a narrower scope of the food system. A team of HCI researchers discovered they inadvertently created an information power dynamic in which farmers provided their operational data (i.e., relinquishing ownership) to cooperative technicians via a tool to better understand their own immediate production costs but were not aware of ways that the technicians were using their data, in conjunction with other farmers' data, within the cooperative [45]; this issue was addressed in a second iteration design [46]. Given the collective findings of the ongoing explorations into sustainable food research, HCI researchers asserted that the paradigms and practices of HCI research risk perpetuating the unsustainability of food and agriculture systems [62].

Our paper contributes to this particular area of research by presenting a case study that explores the values and nuances of the sustainable food systems created and used by the participating communities with the intent to inform the design of information systems in ways that challenge the normative paradigms for HCI design and instead aligns with the communities in ideals and practice. The participating communities of the research presented in this paper do work and have values that overlap, though not entirely, with several other communities presented in this section, and similarly digress from much of the work and values traditionally studied in HCI, especially in contrast to the ever-popular focus on the individual [13, 17, 18, 65]. Five years ago, Håkansson and Sengers argued there are many ways to make change and encouraged HCI to diversify "the ways we make change to make change-making itself more sustainable" [29, p. 1031]. This paper joins the others in demonstrating how the lessons learned by the permaculture community in pursuing and supporting food sustainability activism can be more broadly applied to HCI.

\section{RESEARCH CONTEXT}

This section describes the participating subject communities, the applied research methods, and the data analysis process.

\subsection{Participating Communities}

Throughout this paper we discuss two participating communities of practice. Both permaculture communities were in the United States, one in the humid subtropics of the Southeast coast and the other in the Mediterranean climate of the Southwest coast. To protect the privacy of these communities and the participants in this research they will be referred to as the Live Oak and Manzanita communities, respectively, after prominent trees from the local ecology. We also refer to these communities' geographical locations as Live Oak and Manzanita; however, these are not the true names of these geographical locations.

Dewey [15] defines a public as a group of people addressing a common problem, or the indirect effects of a common problem, in the same manner. Just as publics are constructed to address a common problem, they in turn dissolve as the common problem is solved. The participating communities were, in effect, publics using permaculture and agroecosystem techniques to address food security, climate change, and environmental degradation. Sustainable polycultures are designed to come into maximum effect decades after they are planted because the public is attempting to address issues both in the present, but also issues they anticipate occurring in the long-term. However, the participating communities are better characterized as tiny publics, which Steup et al. describe as small groups for civic engagement that focus on everyday life as the medium for social change [82].

Both permaculture communities were forming when this research began. Participants first explored their interest in permaculture by attending an introductory permaculture design course 
(PDC). Many newcomer permaculture participants were members of the local encompassing grassroots sustainability community, of which permaculture is one sub-community. Some participants were newcomers to both permaculture and the encompassing local sustainability community. Devoted members of the permaculture communities, often self-described as "permies," were also involved in other local sustainability activism. "Permie" is a term informally used throughout the permaculture movement to distinguish full participants from the peripheral, and sometimes uncommitted, participants in a permaculture community. Participants came from a variety of backgrounds including college students, farmers, restaurant owners, medical professionals, landscape designers, computer scientists, and school teachers. They were brought together by their interest in learning how to lead more sustainable lives and particularly interested in exploring sustainable agriculture from the perspective of permaculture.

The first author engaged in the Live Oak Community first as a student, then as an apprentice, and finally as a facilitator in the community's PDCs. The first author also engaged as a participant or volunteer in other community activities, such as planting community gardens or tabling at city festivals. Later, the first author was a facilitator for the Manzanita PDC and served as a volunteer and participant for community activities. The Live Oak and Manzanita communities were unconnected with each other beyond the first author's involvement in each community.

3.1.1 Live Oak Community. The Live Oak permaculture community existed within a larger metropolitan grassroots sustainability activism community, along with a local food cooperative, an organic grower collective, a simple living institute, a holistic medicine school, a university arboretum, and several small sustainability-oriented businesses. The permaculture community founder participated in the local food cooperative as a farmer. Some permaculture participants and students were also students of the local holistic medicine school. Sometimes these interactions were partnerships. For example, the permaculture founder hosted workshops at local businesses, such as a rain barrel installation demo at nearby a sustainable food restaurant. Participants of the greater grassroots sustainability community supported the permaculture faction even though they themselves were not participating. For example, a local farmer waved admission to his workshop about raising chickens for students in the permaculture course.

The permaculture community was initially centered around the founding instructor of the local PDC. The community was approximately one year old when the first author became acquainted with it. In the following years, the once-pupils of the founding instructor practiced and became new instructors or service providers for the community.

By 2013, the Live Oak permaculture community grew to over fifty full participants. Some community members started consultation LLCs, and permaculture installments began popping up in the local area. Some community members focused on establishing home permaculture gardens. Some of the more complex implementations, both residential and civic, became community demonstration sites for using specialty systems in permaculture, such as grey water reclamation, rainwater catchment, and aquaculture. One participant created a permaculture-based elementaryschool curriculum and garden.

3.1.2 Manzanita Community. This sustainability community is located within a predominantly affluent suburban area within a greater metropolitan area. The sustainability education center that we partnered with re-initiated an earlier effort to establish a permaculture community of practice. It did so by offering a PDC for four consecutive years. More than forty-five students attended their PDCs over four years. In the time since the fourth PDC in 2016, a permaculture community has formed beyond the sustainability education center, which has increased the opportunities for newcomers to observe and engage in permaculture practice alongside experienced community members. Most of the small but growing number of leaders and experienced participants do have 
prior affiliations with the center, either as staff or students of that PDC. Very recently (2018) these new leaders hosted several PDCs and other community meet-ups at multiple institutions, thus building the potential to grow and sustain the permaculture community of practice.

\subsection{Methods}

The research presented in this paper is the value-elicitation component of an action research initiative to design and develop information systems for two permaculture communities. Action research is the process of conducting research with community members to improve a situation [47]. HCI researcher Gillian Hayes [34, p. 49] argues that action research "offers a systematic collaborative approach to conducting research in HCI that satisfies both the need for scientific rigor and promotion of sustainable social change." Our findings emerged from four forms of qualitative data: observation notes, surveys, interviews, and workshop recordings and outcomes. These multiple forms of data allowed for triangulation on the core themes of the communities' values. The data set encompasses 6 years of field data, including observations, survey data, interviews, and workshop notes, from two communities of roughly 50 people each (with the fluctuations to be expected in such communities of interest).

3.2.1 Observations. The first author recorded her observations by writing notes while participating in PDCs, workshops, and other community events. Her early notes were predominantly taken from a student perspective. As our research began to take a more defined shape, her participation notes included research-based observations as well. At the end of each activity with the Manzanita community she wrote "thick descriptions" [26] of the day's events, taking care to provide cultural context and critical thoughts for her observations. A thick description not only describes the observed behavior, but also the context of that behavior including explanations and meanings defined by the participants engaging in the behavior [53].

3.2.2 Survey. We distributed an exploratory open-ended survey to the Live Oak community. Fourteen members of the community who had been active for at least one year responded to the survey. The survey asked participants about their use of technology, digital and otherwise, in the design of sustainable polycultures. Participants discussed which features of the information technology they used support and which discourage their practices.

3.2.3 Interviews. We conducted 30-minute to one-hour semi-structured interviews with five newcomer participants of the Manzanita community. All of the interviewees were in their first year of participating in the community. The first author conducted these interviews to gain additional insight to their learning experience, how information technology affected their learning process, and how they used information technology in their design projects. She conducted these interviews during breaks or after educational sessions in Manzanita PDC-2014. She audio recorded all interviews and transcribed the recordings within one week of the interview.

3.2.4 Workshop: Creating a Common Design Future. Permaculture designers create sustainable polycultures that naturally regenerate and support long-term goals - goals with a time horizon of many human generations or longer. We invited the participants of the Manzanita Community to participate in a workshop in 2015. The goal of this workshop was to understand the community's shared common design future (to the degree that they have one). Based on DiSalvo's [16] tactics that support the design and construction of publics, we designed the workshop to guide community members in the projection of their society in a potential future scenario of their creation. Then we guided participants in the tracing of critical artifacts (e.g., food, water, and energy) that are implicated in or effected by the nature of the future scenario. 
In $\mathrm{HCI}$, using fictional futures to explore implications for technology design with speculative design or design fiction is an accepted and valued practice. Tanenbaum et al. [85, p. 3] argue that design fictions, typically films about the future, highlight "values and intellectual commitments associated with a new technology." Hauser, Desjardin, and Wakkary [33] used design fiction to "unlock people's imagination, encourage reflection, and inspire action towards a more sustainable reality" at their university. Dunne and Raby [19, p. 102] use speculative designs to "question the meaning of technology itself" in an effort increase the opportunity of achieving desirable futures. Baumer et al. [4, p. 762] created and curated abstracts for papers that could be published at $\mathrm{CHI}$ in 2039 to explore "what will constitute rigorous, publishable research in the future." In this workshop, the process of constructing a design future allowed participants to critically analyze the long-term values of the Manzanita sustainable agriculture community and how those values could and should be supported and represented by information technology ${ }^{1}$.

\subsection{Data Analysis}

We analyzed the observation, interview, and survey data using established coding and categorizing techniques for qualitative data $[49,77]$ to understand the extent and nature of such values. Saldaña characterizes coding as deciphering what an artifact or passage of data means and then encoding that meaning with a label [77]. Coding is largely an "interpretive act" [77] and allowed us to gain a first impression of the data. For anonymity, all names in the data have been replaced by pseudonyms. All mention of names in field notes and transcriptions were de-identified using an online name generator.

We coded and categorized the workshop data to understand the community's long-term values and visions regarding technology, agriculture, environment, and social structure. We utilized the emerging themes regarding long-term technology, agriculture, environment, and social values and visions to guide the formation of a shared likely future scenario and to iterate on the concept of a suite of sociotechnical systems for the community. In addition to transcribing the audio, we referred back to the individual participant's hand-written worksheets for clarification of points made in the group conversation. The group could also create a shared desirable scenario if the emergent likely scenario is not a desirable one. After completing this process, we shared the synthesis of the design future with the participants inviting feedback and changes, and two participants made edits or otherwise provided clarifications.

\section{PERMACULTURE COMMUNITY VALUES}

The core permaculture ethics and principles described in the Introduction serve as an explicit philosophical foundation for permaculture practice. In addition, through our study we found three other values sets that are commonly held in these communities: technology values, long-term values, and resistance values.

\subsection{Technology Values}

Participants used ITs to address problems of sustainability, particularly in the context of agriculture. Participants depended upon ITs in three contexts: (1) design of (typically agricultural) infrastructure, (2) coordinating design projects and community events, and (3) independent learning. Participants used ITs during the permaculture design process. Participants used publicly available information on the Internet (e.g., Google satellite maps, USGS topographic and soil maps, climate and weather databases, and historical land ownership government websites) to create maps and profiles for design sites. They used online plant databases for determining the flora components of a design.

\footnotetext{
${ }^{1}$ http://perennialpolycultures.ics.uci.edu/
} 
Some participants used 2D and 3D drawing software (e.g., Adobe Photoshop and SketchUp) to refine their designs. Participants also used word processors and spreadsheet applications for office and business management.

Participants found that ITs improved their work by helping them accomplish tasks faster, more accurately, and at lower cost. One student in the Manzanita PDC explained how he was able to reduce the time needed to accomplish a task using IT: "We are able to get a great understanding of weather over a year without observing for that long." Another explained how ITs provided them with data essential to the design process: "Satellite images provide accurate top-down perspectives of the site and surrounding area that we wouldn't otherwise have."

Participants used email, phone, text messaging, and instant messaging to coordinate with others. One participant used Survey Monkey (a survey website) to distribute client needs surveys. Several participants used Doodle polls and chat features in Google Docs to coordinate with peers or clients. Participants used Facebook, Meetup, and email to coordinate and share information at the community level. The Live Oak community had a periodic email newsletter and website for announcements and shared event information.

Although participants used ITs to address challenges of sustainability, they had two philosophical misgivings in doing so: (1) negative environmental impacts of IT manufacture, use, and disposal; and (2) distraction from physical human and environment interaction. These misgivings are not, however, unique to these permaculture communities. ITs are known by HCI researchers to be implicated in the problems of sustainability $[5,17,88]$ and social isolation $[1,75]$.

In accordance with the core principles of the permaculture movement, participants preferred utilizing renewable and local resources to non-renewable or distant resources [37]. However, nonrenewable resources, often from distant places, make up and power nearly all aspects of IT. This misgiving can explain some of the intentional non-use of ITs that we observed. Some participants utilized and repaired old laptops and mobile devices with the intent of keeping the technology working as long as possible. Others focused on reducing operational energy from non-renewable resources. For example, one participant kept his phone powered off until he needed to make a phone call or was ready to check for messages. Many other participants in the Live Oak community owned small solar cells that they used to charge their small electronic devices, such as cell phones.

The second misgiving arises from the neglect of social interaction with people and other living things in the physical environment when using ITs. A core principle of the permaculture movement calls for a "culture of place" that connects people to each other, the land, and nature [38]. Participants believed that face-to-face social interaction is more effective for forming community than ITmediated interaction because ITs pull attention away from the physical environment including people and nature. Thus, participants engaged in selective use of technology, a form of technological non-use as described by Baumer et al. [6]. Participants believed that reducing or eliminating their use of ITs for a period of time allowed them to value social connections. For example, one participant described his decision to use a basic phone rather than a smart phone in order to avoid distractions and improve his in-person interactions:

"I used to have a smart phone, but I got rid of it. I was at the student union one day and realized that everybody was looking at their smart phone or listening to music with headphones instead of getting to know each other. I feel like that happens everywhere. I didn't like that I was missing out on what was happening around me or that I sometimes found what was happening on my phone to be more important than what somebody was saying to me. I like the interaction I have with people better now. I often leave my phone somewhere and don't think about it for hours. It's refreshing." 
The research in this paper was completed in a high-income country where there is general access to IT and infrastructure. We are aware that the opportunity to make choices about whether or not to give away one's smartphone or whether to stick with older technology instead of buying a new edition would often not be an option in subsistence farming communities as described, for example, by Leshed et al. [46] and Oduor et al. [64].

\subsection{Long-Term Values}

Most participants believed that societal collapse was inevitable or would be if modern societal norms, and in particular rampant extractivism and consumerism, did not change. Most participants believed that natural disaster, ecological crisis, and resource depletion were the most imminent threats to society. They framed modern financial systems as the culprit, believing that an overhaul of the financial sectors away from extractivism and consumerism is fundamentally necessary to address local and global ecological crises. For the participants facing evidence of resource scarcity, there was not a question of if the financial sector would eventually collapse if extractivism continued, but of when and how severe the ecological impacts would be in their and future generations' lifetimes. Klein has beautifully summarized the participants' sentiments regarding the implications of extractivism on global ecological collapse [40, p. 21]:

"What the climate needs to avoid collapse is a contraction in humanity's use of resources; what our economic model demands to avoid collapse is unfettered expansion. Only one of these sets of rules can be changed, and it's not the laws of nature."

The participants believed that by engaging in permaculture, they could reduce their own and their communities' ecological footprint, foster the regeneration of natural resources, and be prepared for a collapse.

The issues addressed by these communities-climate change, resource scarcity, societal limitations, and food security-are considered multi-lifespan problems. When exploring how to address these multi-lifespan problems, the community demonstrated three interrelated values: food sovereignty, regenerative design, and sociocultural equality. These values are influenced by the core permaculture ethics and principles, which participants regularly discussed-particularly in the educational setting.

Food sovereignty for this community may be better described as critical resource sovereignty because the objective of permaculture is to obtain and manage all critical resources, also including energy and water, for sustainable human settlements [54]. Altieri's explanation of food sovereignty reflects the nature of these communities' values of food sovereignty-food sovereignty emphasizes "farmers' access to land, seeds, and water while focusing on local autonomy, local markets, local production-consumption cycles, energy and technological sovereignty, and farmer-to-farmer networks" [2, p. 104]. With long-term personal water collection and recycling features, and passive and active solar energy utilization, participants aim to achieve long-term local, and even personal, autonomy of critical resources. Specifically, the communities' long-term food sovereignty values encourage the formation of an agrarian society in place of the industrial society we have now.

Regeneration denotes breakdown, evolution, and growing anew. On the surface, regeneration could counter the "permanent" in permaculture. However, participants did not value permanence in the sense of unchanging. For participants, permanence required the ability for something to change with and adapt to slow, multi-lifetime changes and problems, such as climate change and resource scarcity. Participants applied the value of regeneration to the community itself-evolving its goals and values to global and local changes and fostering the arrival of newcomers and the passing of old-timers. They also applied the value of regeneration to renewable and non-renewable resources-facilitating the regeneration of natural resources, like using earthworks to sink rain 
and irrigation water into the ground, and chemical exchanges, like amending soil with biochar for carbon sequestration. Furthermore, they applied the value of regeneration to infrastructurecreating agricultural systems that function as ecosystems, like sustainable polycultures, and using waste to create energy, like breaking down organic material in biodigesters to create biogas. Finally, participants applied the value of regeneration to technology, indicating an interest in hardware components and power sources that could grow and decompose.

Sociocultural equality, as described by these communities, entails a society of people who have equal opportunity to participate in the formation and possession of sociocultural capital, knowledge, critical resources, infrastructure, and traditions. Achieving equality is contingent upon sociocultural equity, which entails providing all people with the resources they need to be successful. Broadly, participants view the current industrial society as one that fosters inequality and disenfranchisement. They envision a future sustainable agrarian society that disaggregates and disperses wealth and provides people with the opportunity to have direct engagement with their community and its economy. They believe long-term collective action can transition their communities from the current industrial society to a future sustainable agrarian society.

Although most participants shared these long-term values, they disagreed on the likelihood of future societies representing these values. One participant described these ideals as "probably unrealistic" and "utopian in nature," but nevertheless longed for food sovereignty, regeneration, and equality in society. Another participant challenged that assessment, pointing out that most of the participants had already agreed that some sort of collapse was likely to occur. If society collapses in thirty years, he posited, in every moment up to and through that point, they should be laying the foundation for a more just and sustainable society. In summary, community members shared long-term values but disagreed on if those long-term values can be achieved.

\subsection{Resistance Values}

The manner in which participants worked to achieve and sustain their long-term values varied. For most participants, engaging in permaculture was, to some degree, a form of activism. It was an explicit attempt to resist and change unsustainable agri-eco-socio-techno-economic systems, or at the very least the current industrial food and agriculture system. Instead of the regulated, efficiencyfocused nature of modern agricultural institutions, participants work towards independence, selfreliance, personal-value-respecting food and agricultural production. However the degree to which participants' practices attempted to resist or change unsustainable sociotechnical systems varied. We found that participants engaged in two forms of resistance-quotidian insubordination and appeals for institutional and social change. In addition, we observed resistance regarding the use of IT as described in Sec. 4.1, for example restricted use, refusing to upgrade, or even stopping usage.

4.3.1 Quotidian Insubordination. Political scientist and anthropologist James Scott describes everyday forms of resistance, or "quotidian insubordination," as relatively low risk, anonymous, and obscure [79]. Quotidian insubordination, Scott says [79, p. 12], "flies under the archival radar, waves no banners, writes no manifestos."

The most common acts of quotidian insubordination by the participants had an anti-consumerist and subversive overtone, such as buying second hand or used materials, not buying or using single use goods like plastics, or trading goods or services instead of using money. While these are not illegal, Naomi Klein argues how they insubordinate the domination of capitalism, as prevalent in the US [40, p. 173]: "just as colonialism needed coal to fulfill its dream of total domination, the deluge of products made possible by both coal and colonialism needed modern capitalism."

The most stated forms of quotidian insubordination by the participants included ripping up grassy front yards to plant gardens, collecting rain water, raising backyard chickens, and guerrilla 
gardening. The more outspoken participants suggested that they engaged in these acts in peaceful protest to industrial and governmental infrastructures that regulate their daily lives.

An individual that grows their food, collects their rain water, and prioritizes second-hand traded over new purchased goods is resisting the controlling infrastructures by not participating in them. When this behavior is socially accepted among those engaging in permaculture or other sustainability communities, and neighbors are complicit because they do not report the unlawful behavior, it begins to function as an unorganized form of collective action.

Guerrilla gardening was arguably the most subversive occurrence of the communities' acts of quotidian insubordination. A small subset of participants in the Live Oak community met on a weekly or biweekly basis and planted seeds and young plants in typically fallow areas on both private and public property. Although this was an illegal act, the guerrilla gardeners believed that leaving the land fallow was more problematic then trespassing or hijacking the space for their own social agenda. The guerrilla gardeners gathered just after sunset, each bringing seeds or plants from their personal store and basic hand tools. They typically rode bikes to their target locations and wore dark clothing in effort to be inconspicuous.

When we asked the guerrilla gardeners how they anticipated the plants would grow and the food would get harvested, they explained that a successful harvest was secondary to making a social statement. Many of the plants would not grow well enough to produce a bountiful harvest because the plants are unmanaged-they do not have consistent irrigation, only rainfall, nor are they growing in properly amended soil. Also, some of the sites were fenced, and most citizens are unlikely to trespass beyond a fence for fruits and vegetables of questionable origin. Instead, it was their goal that someone would notice that food was growing in once vacant, fallow space, that the local society would learn that food could grow in unusual places in an urban and suburban environment, and that the local government would notice that its citizens want more local, sustainable food production. However, when collective action creates a noticeable effect, government and industry retaliates and explicit resistance is born [79].

4.3.2 Appeals for Institutional and Social Change. Unlike the anonymous acts of quotidian insubordination, appeals for institutional and social change were meant to be noticed. For example, the Live Oak sustainable agriculture community appealed to the local government regarding the right to grow food in front yards. This began when a gardener in Live Oak was cited by the city for not having appropriate ground cover in his front yard as, instead of grass, he had a garden. This and similar events, shared through social media and word of mouth, motivated individuals to lobby for new and changed city ordinances, run for local office, or run for their homeowners' association (HOA) board in order to change the institutions they were living within. On several fronts, the Live Oak sustainable agriculture community was successful. For example, in the last five years several counties in Live Oak have started programs to help people raise chickens in their suburban back yards.

We witnessed similar forms of striving for institutional change by the Manzanita community. One participant petitioned against the use of pesticides on school grounds from her children's district to the state. As more community members began installing gardens in their children's schools, the movement to ban pesticides on school grounds became a community effort. Although the group's effort was unsuccessful, the community's awareness surrounding the issue has increased.

Participants also joined marches and demonstrations. Some younger participants of the Live Oak community were enraged by the capitalist infiltration of ecological conservancy and social sustainability institutions, information they gleaned from online news sources and social media platforms like Facebook, and so participated in local Occupy Movement marches and demonstrations, which were advertised via flyers, word of mouth, and on platforms like Facebook and Meetup. 
Other members of the Live Oak community regularly participated in a monthly bicycle critical mass to "to raise awareness and promote the safety of non-motorized modes of transportation when sharing the streets with motor vehicles."

In summary, the manner in which most participants engaged in permaculture was to resist and change unsustainable norms and standards of the existing agri-eco-socio-techno-economic systems they live within. These activities ranged from subtle to obvious and from working within the system to change it to subverting the system all-together.

\section{DISCUSSION}

\subsection{Moving Sustainable Food and Agriculture Community Values into the Mainstream}

Many of the values of these permaculture communities overlap with the communities introduced in the related work. For example, the organic food community Bødker et al. [10] researched also have local sustainable food production, community collaboration, and knowledge sharing. The small farmers associated with a local food movement from Steup et al.'s research [82] demonstrated values towards a professional and appealing reputation, particularly in their selective transparency not to show the hardships of small local farming. There was a similar sentiment among the permaculture communities to present themselves and information in an appealing light, which they dubbed "making permaculture sexy." The focal values of the farm families in Leshed et al.'s research [44] overlap with the peripheral values of our participating permaculture communities, including merging home and work life in such a way that supports the natural rhythms of family life, unmediated face-to-face interaction, being outside, and a person's ability to multi-class in their roles.

Much of the work by the permaculture communities overlapped with the work by the communities introduced in the related work. For example, many members of the permaculture communities were planning homesteads - a variant of a family farm such as those Leshed et al. [44] researched. Some of the unusual conditions of Leshed et al.'s farming families, specifically the nature of the laborious outdoor work and the importance of natural rhythms (e.g., seasons) [44], were shared by our participating communities more broadly. Most digital technologies are sensitive to the weather and rough handling encountered during manual labor on the family farm [44]. The same is true for digital technologies on permaculture sites.

These examples of shared sets of values and work across distinct communities engaged in food and agriculture sustainability demonstrate that they are common rather than rare, normal rather than unusual, and significant rather than unimportant. It is time to move sustainable food and agriculture community values into the mainstream focus of $\mathrm{HCI}$ and $\mathrm{CSCW}$ research because business as usual has failed to support these communities thus far. Similar to the ecovillage communities that Nathan studied [59], our previous work reports that the permaculture communities faced significant information challenges that caused unsustainable information architecture and organization complexity that were antithetical to the communities' core values [61]

. Because we have evidence that they attempt to transfer their sustainability values to their information practices 4.1 , we hypothesize that this mismatch occurs because their values are not supported by the technological infrastructures they are using. This is something that our communities want to change, and asked us to help change. For those in HCI and CSCW who engage in UX design and development to support these communities' work, we must understand those values, especially those that are implicit, and how the sociotechnical systems we design support or undermine them. Perhaps that the best way for those of us doing that work is to be a member of the community. 


\subsection{Unsustainability of Sociotechnical Complexity}

ITs for this group should work within their selective use values. These communities engaged in selective use of IT due in large part to its implications for sustainability. Baumer and Silberman [5, p. 2271] argued that "it is not obvious that the complex conditions associated with unsustainability ... are best addressed with computing technology." Tainter offers that although complex system can be very effective at addressing social problems such as sustainability, at some point the complexity of the system becomes so great that the returns are marginal [84]. If the complexity is left unconstrained, Tainter argues, diminishing returns become negative, meaning the system is ineffective at problem solving, and the system (or society) is vulnerable to collapse.

These communities do not desire yet another complex sociotechnical solution with marginal returns. Sociotechnical interventions are not always well thought out solutions. Bødker [9] explains that in the third wave of HCI, researchers rapidly designed and introduced ITs in an exploratory fashion, typically with short-lasting or little impact, to understand which questions to ask. In effect, Bødker [9, p. 26] argues, the discipline has "just dump[ed] technology on people." Indeed, the inundation of technology and the marginal returns from those technologies have made the participating communities more critical of technology.

Bødker also described the increasingly common phenomenon of "technologies that reach into all corners of life" [9, p. 26]; however, members of these communities commonly find that technology distracts them from other interactions that they desire more strongly (e.g., with people or nature), and therefore frequently make an effort to conduct their lives without the disturbance of technology. A technology that is designed to follow them into all corners of their life is at odds with this way of living; these communities typically prefer to use technology selectively rather than ubiquitously.

One way to address the complex sociotechnical conditions associated with unsustainability is by ensuring the IT systems empower the communities and provide their members with agency so that they can sustain themselves in the absence of the IT. This builds on work by Tomlinson et al. [88], who describe the concept of self-obviating systems: those that render themselves unnecessary by offering some service that solves or addresses a problem. In other words, the IT's impacts remain even after it is removed from the information ecology. For example, an IT system that teaches the community how to design sustainable food systems could facilitate the transition of enough newcomers to full participants to encourage face-to-face social learning as the community norm, rendering the information system un- or less necessary in the long-term as that knowledge becomes a part of the community's sociocultural capital. In relation to long term IT design, both Yoo et al. [96] as well as Friedman and Nathan [25] look at multi-lifespan design thinking for information systems and find it limited by the human psyche, societal structures, and the comparative slowness of natural time-scales.

Raghavan and Pargman have also suggested a framework for addressing sociotechnical conditions of unsustainability that work within the limits of these communities' values. Considering Tainter's argument in the context of sociotechnical systems, Raghavan and Pargman suggest simplifying system complexity through the software concept of refactoring [71]. Refactoring software is the process of applying techniques that makes code more efficient and readable, breaking down complex functionality into simpler parts, and limiting external inputs. Applying these same techniques to sociotechnical systems, Raghavan and Pargman argue, could productively address their issues of growing complexity. The concept of sociotechnical refactoring is particularly appropriate for permaculture communities in part because it overlaps with permaculture practices. Specifically, permaculture aims to limit external inputs to their sustainable polycultures. For example, in a polyculture, nutrients for plants should be provided by other plants in the ecosystem or from on-site compost rather than off-site fertilizer. Therefore, an IT created for a permaculture community

Proc. ACM Hum.-Comput. Interact., Vol. 3, No. CSCW, Article 34. Publication date: November 2019. 
that curbs the external inputs into their agroecosystems or information ecology will be better at addressing the community's complex conditions associated with unsustainability than an IT that does not. If an IT cannot effectively contribute to refactoring the sociotechnical system, then, as Baumer and Silberman [5] argued, sometimes the implication is not to design technology.

Other implications of these communities' value on the design of systems include the capacity for anonymity, the ability to support community, and adaptability to many different platforms. For example, if an IT is designed to support some form of quotidian insubordination, such as producing and trading open-pollination seed and plants, and participants prefer to engage in these acts anonymously, then ITs for this group need to allow for anonymous usage and interaction. Furthermore, those ITs should support the community more broadly and act as a community asset, not subject to heteromation (the occurrence of a single person or entity financially benefiting from the work of an unpaid or underpaid community [21]). Heteromation is directly at odds with the community's anti-consumerism and long-term equality values. ITs for these communities need to be "open," not proprietary, so the communities can adapt the system to match their evolving needs. Also, ITs for these communities need to work across a range of platforms and operating systems, from new to very old, from mobile to desktop, and work even with intermittent internet connectivity.

Very often, designers build information systems that uphold their own self- or organizationserving values and goals, such as popularity by way of mass production of short-lifespan products (followed by e-waste) [74], profit by way of aggregating value from free labor (i.e., heteromation) [21], innovation via exploitation of Earth's natural resources [78], or social change by way of mass adoption (i.e., technology evangelism) [91]. However, many permaculture participants were willing to abandon technologies that were implicated in a social or environmental issue, such as certain brands of smartphones, laptops, and other devices that have rechargeable lithium ion batteries (since they contain coltan, mining of which has led to substantial ecological and human security impacts in the Congo) [23]. Since participants were willing to forgo ubiquitous technologies or technological services because they were in conflict with their values, it is imperative that technologies designed for these communities are in support of, and certainly not in conflict with, their values.

Many of these communities' permaculture, resistance, technological, and long-term values represent important constraints on the adoption of modern ITs. However, we believe that these constraints on computing involve aspirational moral principles and ideals. These principles have the potential to effectively guide the design and development of ITs that are geared toward addressing complex sociotechnical conditions associated with unsustainability in a manner that is morally acceptable to many sustainability activists.

\subsection{Envisioning ITs For Permaculture Communities}

The question arises what the successes and challenges are of using values from one domain (e.g., permaculture or sustainability) to shape IT. In working with the participating permaculture communities, we conceptualized a suite of tools based on the communities' illustrative vision of sustainable agriculture in 2045. They illustrate where we need to design (evaluated according to Baumer and Silberman [5]), because of information needs that are not covered by existing systems [28], and describe two of them in the following.

We designed and developed one tool, a plant database to support the communities' work in creating and maintaining sustainable polycultures. We have designed this tool in particular to meticulously support the values of the communities. For example, the ontology was derived from the communities' sustainable polyculture design process, including which plant characteristics provided ecosystem service and human value. The data is being elicited from resources the community used 
such as books, other plant data resources used by the community, and people from within the community. Using resources approved by the community was a first step to ensure that the data in their database supported the values of their community. The tool was also designed to support the unique work environment of permaculture farmers, specifically in that it is designed to work online to support collaboration, but also available for download to work offline for remote field work. This is only a short list of examples in the ways that the communities' values were incorporated in the design of this tool, for more information see [61].

Another tool in the suite is envisioned to coordinate the design of sustainable polycultures and other infrastructures within neighborhoods to form sustainable polycultures. It facilitates users' coordination in space, in time, and many different processes such as pollination. Some plants need nearby plants of the same species for wind (i.e., anemophily) or animal pollination (i.e., zoophily). It will help communities form strategies that rely on and encourage local food system production capacity, resilience, and satisfaction of food needs and preferences. With the coordination tool, users could make their outputs available for trade, purchase, or other transactional means outside of the established economic model, if so desired.

\section{CONCLUSION}

This paper introduced the values of two permaculture communities that impact their information system design and use. These long-term, resistance, and technology values yielded a set of implications for information system and technology design not often considered by mainstream academic and industry HCI. Most common-place sociotechnical systems are unsustainable because they are built to meet goals that are at odds with long term sustainability, such as the aggregation of money and power and other short-term goals. We demonstrated how such unsustainable features are also antithetical to the participating communities values and practices. Developing information systems based on the values and practices of sustainability communities such as those that participated in this work has the potential to transform the information system landscape to one that can support the design and development of sustainable agriculture, if not to one that is broadly sustainable and equitable.

Harrison, Tatar, and Sengers [32] explain that meaning is derived from information and that meaning is dependent on viewpoints, interactions, histories, and local resources to make sense of that information. These communities shared common core values and information from the permaculture movement which lead to an overlap in community-specific long-term, resistance, and technology values. With thousands more permaculture communities in the world, not to mention other grassroots sustainable agriculture communities, these long-term, resistance, and technology values are a relatively common set of values that warrant rigorous exploration and consideration in $\mathrm{CSCW}$ and $\mathrm{HCI}$ research. However, because of the potential variance in meanings based on interactions, histories, and local resources, it is important that we do not assume that one permaculture or sustainable agriculture community is the same as the others and that a information system or technology for one community will work for another.

Action research initiatives such as this one can guide designers toward information system solutions that support the communities they are working with. Though they may not be tailored to any other specific community, resulting information systems may provide other communities with better suited technologies than the ones created for a general, tech-enthusiast population. If the technologies we design for specific communities are open for adoption and revision, other communities that derive similar meaning from environmental and social information suddenly have the ability to modify or tailor tools rather than build from scratch or conform to the vastly different values embedded in other tools. 


\section{ACKNOWLEDGMENTS}

This material is based upon work supported by the National Science Foundation under Grant No. CCF-1442749. Thank you to Bonnie Nardi, Don Patterson, Josh Tanenbaum, and Rebecca Black for your feedback on this research and text.

\section{REFERENCES}

[1] Dohyun Ahn and Dong-Hee Shin. 2013. Is the social use of media for seeking connectedness or for avoiding social isolation? Mechanisms underlying media use and subjective well-being. Computers in Human Behavior 29, 6 (Nov. 2013), 2453-2462. https://doi.org/10.1016/j.chb.2012.12.022

[2] Miguel A. Altieri. 2009. Agroecology, Small Farms, and Food Sovereignty. Monthly Review; New York 61, 3 (Aug. 2009), 102-113. https://search.proquest.com/docview/213161892/abstract/1F01D68C0BE44203PQ/1

[3] Danny Ardianto. 2014. Understanding social media-enabled participation and resilience in urban farming communities. ACM Press, 111-114. https://doi.org/10.1145/2686612.2686627

[4] Eric P.S. Baumer, June Ahn, Mei Bie, Elizabeth M. Bonsignore, Ahmet Börütecene, Oğuz Turan Buruk, Tamara Clegg, Allison Druin, Florian Echtler, Dan Gruen, Mona Leigh Guha, Chelsea Hordatt, Antonio Krüger, Shachar Maidenbaum, Meethu Malu, Brenna McNally, Michael Muller, Leyla Norooz, Juliet Norton, Oguzhan Ozcan, Donald J. Patterson, Andreas Riener, Steven I. Ross, Karen Rust, Johannes Schöning, M. Six Silberman, Bill Tomlinson, and Jason Yip. 2014. CHI 2039: Speculative Research Visions. In CHI '14 Extended Abstracts on Human Factors in Computing Systems (CHI EA '14). ACM, New York, NY, USA, 761-770. https://doi.org/10.1145/2559206.2578864

[5] Eric P.S. Baumer and M. Six Silberman. 2011. When the implication is not to design (technology). ACM Press, 2271. https://doi.org/10.1145/1978942.1979275

[6] Eric P. S. Baumer, Jenna Burrell, Morgan G. Ames, Jed R. Brubaker, and Paul Dourish. 2015. On the importance and implications of studying technology non-use. interactions 22, 2 (Feb. 2015), 52-56. https://doi.org/10.1145/2723667

[7] Eli Blevis. 2007. Sustainable Interaction Design: Invention \& Disposal, Renewal \& Reuse. In Proceedings of the SIGCHI Conference on Human Factors in Computing Systems (CHI '07). ACM, New York, NY, USA, 503-512. https: //doi.org/10.1145/1240624.1240705

[8] Eli Blevis and Susan Coleman Morse. 2009. SUSTAINABLY OURS: Food, Dude. interactions 16, 2 (March 2009), 58-62. https://doi.org/10.1145/1487632.1487646

[9] Susanne Bødker. 2015. Third-wave HCI, 10 Years Later-participation and Sharing. interactions 22, 5 (Aug. 2015$), 24-31$. https://doi.org/10.1145/2804405

[10] Susanne Bødker, Henrik Korsgaard, and Joanna Saad-Sulonen. 2016. 'A Farmer, a Place and at Least 20 Members': The Development of Artifact Ecologies in Volunteer-based Communities. In Proceedings of the 19th ACM Conference on Computer-Supported Cooperative Work \& Social Computing (CSCW '16). ACM, New York, NY, USA, 1142-1156. https://doi.org/10.1145/2818048.2820029 event-place: San Francisco, California, USA.

[11] Alan Borning and Michael Muller. 2012. Next Steps for Value Sensitive Design. In Proceedings of the SIGCHI Conference on Human Factors in Computing Systems (CHI '12). ACM, New York, NY, USA, 1125-1134. https://doi.org/10.1145/ 2207676.2208560

[12] Geoffrey C. Bowker and Susan Leigh Star. 1999. Sorting things out: classification and its consequences. MIT Press, Cambridge, Mass.

[13] Hronn Brynjarsdottir, Maria Håkansson, James Pierce, Eric Baumer, Carl DiSalvo, and Phoebe Sengers. 2012. Sustainably unpersuaded: how persuasion narrows our vision of sustainability. ACM Press, 947. https://doi.org/10.1145/2207676 2208539

[14] Graham Burnett. 1999. Permaculture Mandala. (1999). http://spiralseed.co.uk/

[15] John Dewey and Melvin L. Rogers. 2012. The Public and Its Problems: An Essay in Political Inquiry. Penn State Press. Google-Books-ID: M16E5ORLJqIC.

[16] Carl DiSalvo. 2009. Design and the Construction of Publics. Design Issues 25, 1 (Jan. 2009), 48-63. https://doi.org/10. 1162/desi.2009.25.1.48

[17] Carl DiSalvo, Phoebe Sengers, and Hrönn Brynjarsdóttir. 2010. Mapping the landscape of sustainable HCI. In Proceedings of the SIGCHI Conference on Human Factors in Computing Systems. ACM, 1975-1984. http://dl.acm.org/citation.cfm?id= 1753625

[18] Paul Dourish. 2010. HCI and Environmental Sustainability: The Politics of Design and the Design of Politics. In Proceedings of the 8th ACM Conference on Designing Interactive Systems (DIS '10). ACM, New York, NY, USA, 1-10. https://doi.org/10.1145/1858171.1858173

[19] Anthony Dunne and Fiona Raby. 2013. Speculative everything: design, fiction, and social dreaming (1st edition ed.). The MIT Press, Cambridge, Massachusetts ; London. 
[20] Callum Egan and David Benyon. 2017. Sustainable HCI: Blending Permaculture and User-experience.. In Proceedings of the 2017 ACM Conference Companion Publication on Designing Interactive Systems (DIS '17 Companion). ACM, New York, NY, USA, 39-43. https://doi.org/10.1145/3064857.3079115

[21] Hamid R. Ekbia and Bonnie A. Nardi. 2017. Heteromation, and Other Stories of Computing and Capitalism. The MIT Press.

[22] Ingrid Erickson, Lisa Nathan, Nassim Jafarinaimi, Cory Knobel, and Matthew Ratto. 2012. Meta-making: crafting the conversation of values and design. interactions 19, 4 (July 2012), 54. https://doi.org/10.1145/2212877.2212891

[23] Todd C. Frankel. 2016. This is where your smartphone battery begins. Washington Post (Sept. 2016). https://www. washingtonpost.com/graphics/business/batteries/congo-cobalt-mining-for-lithium-ion-battery/

[24] Batya Friedman, Peter H. Kahn, and Alan Borning. 2006. Value Sensitive Design and Information Systems. In The Handbook of Information and Computer Ethics. Wiley-Blackwell, 69-101. https://doi.org/10.1002/9780470281819.ch4

[25] Batya Friedman and Lisa P. Nathan. 2010. Multi-lifespan information system design: a research initiative for the hci community. ACM Press, 2243. https://doi.org/10.1145/1753326.1753665

[26] Clifford Geertz. 1994. Thick description: Toward an interpretive theory of culture. Readings in the philosophy of social science (1994), 213-231.

[27] Xinning Gui and Bonnie A. Nardi. 2015. Foster the "mores", counter the "limits". First Monday 20, 8 (July 2015). https://doi.org/10.5210/fm.v20i8.6121

[28] Maria Håkansson and Phoebe Sengers. 2013. Beyond being green: simple living families and ICT. In Proceedings of the 2013 ACM Conference on Human Factors in Computing Systems. ACM Press, 2725-2734. https://doi.org/10.1145/ 2470654.2481378

[29] Maria Håkansson and Phoebe Sengers. 2014. No easy compromise: sustainability and the dilemmas and dynamics of change. ACM Press, 1025-1034. https://doi.org/10.1145/2598510.2598569

[30] Kristin Hanks, William Odom, David Roedl, and Eli Blevis. 2008. Sustainable millennials: attitudes towards sustainability and the material effects of interactive technologies. In Proceedings of the SIGCHI Conference on Human Factors in Computing Systems. ACM, 333-342. http://dl.acm.org/citation.cfm?id=1357111

[31] Dean M. G. Hargreaves and Bob R. L. McCown. 2008. Low-cost, Low-bandwidth Online Meetings Between Farmers and Scientists. In Proceedings of the 20th Australasian Conference on Computer-Human Interaction: Designing for Habitus and Habitat (OZCHI '08). ACM, New York, NY, USA, 271-274. https://doi.org/10.1145/1517744.1517776

[32] Steve Harrison, Deborah Tatar, and Phoebe Sengers. 2007. The three paradigms of HCI. In Alt. Chi. Session at the SIGCHI Conference on Human Factors in Computing Systems San fose, California, USA. 1-18. http://people.cs.vt.edu/ $\sim$ srh/Downloads/HCIJournalTheThreeParadigmsofHCI.pdf

[33] Sabrina Hauser, Audrey Desjardins, and Ron Wakkary. 2014. Sfuture: Envisioning a Sustainable University Campus in 2065. In Proceedings of the 2014 Companion Publication on Designing Interactive Systems (DIS Companion '14). ACM, New York, NY, USA, 29-32. https://doi.org/10.1145/2598784.2602774

[34] Gillian R. Hayes. 2014. Knowing by Doing: Action Research as an Approach to HCI. In Ways of Knowing in HCI. Springer, New York, NY, 49-68. https://doi.org/10.1007/978-1-4939-0378-8_3

[35] Sara Heitlinger, Nick Bryan-Kinns, and Rob Comber. 2018. Connected Seeds and Sensors: Co-designing Internet of Things for Sustainable Smart Cities with Urban Food-growing Communities. In Proceedings of the 15th Participatory Design Conference: Short Papers, Situated Actions, Workshops and Tutorial - Volume 2 (PDC '18). ACM, New York, NY, USA, 18:1-18:5. https://doi.org/10.1145/3210604.3210620

[36] Sara Heitlinger, Nick Bryan-Kinns, and Janis Jefferies. 2014. The talking plants: an interactive system for grassroots urban food-growing communities. ACM Press, 459-462. https://doi.org/10.1145/2559206.2574792

[37] David Holmgren. 2002. Permaculture: Principles and Pathways beyond Sustainability. Holmgren Design Services, Hepburn, Vic.

[38] David Holmgren. 2013. Essence of Permaculture. (2013). https://holmgren.com.au/downloads/Essence_of_Pc_EN.pdf

[39] Esther Jang, Matthew Johnson, Edward Burnell, and Kurtis Heimerl. 2017. Unplanned Obsolescence: Hardware and Software After Collapse. In Proceedings of the 2017 Workshop on Computing Within Limits (LIMITS '17). ACM, New York, NY, USA, 93-101. https://doi.org/10.1145/3080556.3080566

[40] Naomi Klein. 2015. This changes everything: capitalism vs. the climate. Simon \& Schuster paperbacks, New York [etc. OCLC: 951400591.

[41] Bran Knowles, Lynne Blair, Mike Hazas, and Stuart Walker. 2013. Exploring sustainability research in computing: where we are and where we go next. In Proceedings of the 2013 ACM International foint Conference on Pervasive and Ubiquitous Computing. ACM Press, 305. https://doi.org/10.1145/2493432.2493474

[42] Stacey Kuznetsov, Christina J. Santana, and Elenore Long. 2016. Everyday Food Science As a Design Space for Community Literacy and Habitual Sustainable Practice. In Proceedings of the 2016 CHI Conference on Human Factors in Computing Systems (CHI '16). ACM, New York, NY, USA, 1786-1797. https://doi.org/10.1145/2858036.2858363 
[43] Christopher A. Le Dantec, Erika Shehan Poole, and Susan P. Wyche. 2009. Values As Lived Experience: Evolving Value Sensitive Design in Support of Value Discovery. In Proceedings of the SIGCHI Conference on Human Factors in Computing Systems (CHI '09). ACM, New York, NY, USA, 1141-1150. https://doi.org/10.1145/1518701.1518875

[44] Gilly Leshed, Maria H\a akansson, and Joseph 'Jofish' Kaye. 2014. "Our Life is the Farm and Farming is Our Life": Home-work Coordination in Organic Farm Families. In Proceedings of the 17th ACM Conference on Computer Supported Cooperative Work \& Social Computing (CSCW'14). ACM, New York, NY, USA, 487-498. https://doi.org/10.1145/2531602. 2531708 event-place: Baltimore, Maryland, USA.

[45] Gilly Leshed, Liza Mansbach, and Michael Huang. 2018. Designing for Transparency of Coffee Production Costs. In Extended Abstracts of the 2018 CHI Conference on Human Factors in Computing Systems (CHI EA '18). ACM, New York, NY, USA, LBW529:1-LBW529:6. https://doi.org/10.1145/3170427.3188508 event-place: Montreal QC, Canada.

[46] Gilly Leshed, Masha Rosca, Michael Huang, Liza Mansbach, Yicheng Zhu, and Juan Nicolás Hernández-Aguilera. 2018. CalcuCafé: Designing for Collaboration Among Coffee Farmers to Calculate Costs of Production. Proc. ACM Hum.-Comput. Interact. 2, CSCW (Nov. 2018), 149:1-149:26. https://doi.org/10.1145/3274418

[47] Kurt Lewin. 1946. Action research and minority problems. fournal of social issues 2, 4 (1946), 34-46.

[48] Szu-Yu (Cyn) Liu, Shaowen Bardzell, and Jeffrey Bardzell. 2018. Out of Control: Reframing Sustainable HCI Using Permaculture. In Proceedings of the 2018 Workshop on Computing Within Limits (LIMITS '18). ACM, New York, NY, USA, 2:1-2:8. https://doi.org/10.1145/3232617.3232625 event-place: Toronto, Ontario, Canada.

[49] John Lofland, David Snow, Leon Anderson, and Lyn H. Lofland (Eds.). 2006. Analyzing social settings: a guide to qualitative observation and analysis (4th ed ed.). Wadsworth/Thomson Learning, Belmont, CA.

[50] Peter Lyle, Jaz Hee-jeong Choi, and Marcus Foth. 2014. Designing for grassroots food production: an event-based urban agriculture community. ACM Press, 362-365. https://doi.org/10.1145/2686612.2686666

[51] Jennifer C. Mankoff, Eli Blevis, Alan Borning, Batya Friedman, Susan R. Fussell, Jay Hasbrouck, Allison Woodruff, and Phoebe Sengers. 2007. Environmental sustainability and interaction. In CHI'07 extended abstracts on Human factors in computing systems. ACM, 2121-2124. http://dl.acm.org/citation.cfm?id=1240963

[52] Elaine Massung, David Coyle, Kirsten F. Cater, Marc Jay, and Chris Preist. 2013. Using Crowdsourcing to Support Pro-environmental Community Activism. In Proceedings of the SIGCHI Conference on Human Factors in Computing Systems (CHI '13). ACM, New York, NY, USA, 371-380. https://doi.org/10.1145/2470654.2470708

[53] Albert Mills, Gabrielle Durepos, and Elden Wiebe. 2010. Thick Description. In Encyclopedia of Case Study Research SAGE Publications, Inc. https://doi.org/10.4135/9781412957397.n347

[54] Bill Mollison. 1988. Permaculture: a designers' manual (repr ed.). Tagari Publ, Tyalgum.

[55] Bill Mollison, David Holmgren, and Earle Barnhart. 1981. Permaculture One: A Perennial Agriculture for Human Settlements. International Tree Crop Institute USA, U.S.

[56] Bonnie A. Nardi and Vicki O’Day. 2000. Information ecologies: using technology with heart. MIT Press, Cambridge, Mass.

[57] Bonnie A. Nardi, Bill Tomlinson, Donald J. Patterson, Jay Chen, Daniel Pargman, Barath Raghavan, and Birgit Penzenstadler. 2018. Computing within limits. Commun. ACM61, 10 (Sept. 2018), 86-93. https://doi.org/10.1145/3183582

[58] Lisa Nathan. 2009. Ecovillages, Sustainability, and Information Tools. Ph.D. Dissertation. University of Washington.

[59] Lisa P. Nathan. 2012. Sustainable information practice: An ethnographic investigation. Journal of the American Society for Information Science and Technology 63, 11 (Nov. 2012), 2254-2268. https://doi.org/10.1002/asi.22726

[60] Kher Hui Ng, Victoria Shipp, Anya Skatova, and Benjamin Bedwell. 2015. What's Cooking: A Digital Intervention to Encourage Sustainable Food Behaviour Using Mobile and Wearable Technologies. In Proceedings of the 17th International Conference on Human-Computer Interaction with Mobile Devices and Services Adjunct (MobileHCI '15). ACM, New York, NY, USA, 1058-1061. https://doi.org/10.1145/2786567.2794330

[61] Juliet Norton. 2019. Information Systems for Grassroots Sustainable Agriculture. Ph.D. Dissertation. UC Irvine. https: //escholarship.org/uc/item/1ds163pz

[62] Juliet Norton, Nico Herbig, Lynn Dombrowski, Ankita Raturi, Bonnie A. Nardi, Sebastian Prost, Samantha McDonald, Daniel Pargman, Oliver Bates, Maria Normark, and Bill Tomlinson. 2017. A grand challenge for HCI: food + sustainability. interactions 24, 6 (Oct. 2017), 50-55. https://doi.org/10.1145/3137095

[63] William Odom. 2010. "Mate, We Don't Need a Chip to Tell Us the Soil's Dry": Opportunities for Designing Interactive Systems to Support Urban Food Production. In Proceedings of the 8th ACM Conference on Designing Interactive Systems (DIS '10). ACM, New York, NY, USA, 232-235. https://doi.org/10.1145/1858171.1858211

[64] Erick Oduor, Peninah Waweru, Jonathan Lenchner, and Carman Neustaedter. 2018. Practices and Technology Needs of a Network of Farmers in Tharaka Nithi, Kenya. In Proceedings of the 2018 CHI Conference on Human Factors in Computing Systems (CHI '18). ACM, New York, NY, USA, 39:1-39:11. https://doi.org/10.1145/3173574.3173613 event-place: Montreal QC, Canada.

[65] Daniel Pargman and Barath Raghavan. 2014. Rethinking sustainability in computing: from buzzword to non-negotiable limits. In Proceedings of the 8th Nordic Conference on Human-Computer Interaction: Fun, Fast, Foundational. ACM, 
638-647. http://dl.acm.org/citation.cfm?id=2639228

[66] Daniel Pargman and Björn Wallsten. 2017. Resource Scarcity and Socially Just Internet Access over Time and Space. In Proceedings of the 2017 Workshop on Computing Within Limits (LIMITS '17). ACM, New York, NY, USA, 29-36. https://doi.org/10.1145/3080556.3084083

[67] Donald J. Patterson. 2015. Haitian resiliency: A case study in intermittent infrastructure. First Monday 20, 8 (July 2015 ). https://doi.org/10.5210/fm.v20i8.6129

[68] Eric Paulos, Marcus Foth, Christine Satchell, Younghui Kim, Paul Dourish, and Jaz Hee-jeong Choi. 2008. Ubiquitous Sustainability: Citizen Science \& Activism (Workshop). http://eprints.qut.edu.au/14130/

[69] Chris Preist. 2016. Understanding and reducing environmental/energy impact of digital services - Dr. Chris Preist. (May 2016). https://www.youtube.com/watch?v=kUlF95I3Iz8

[70] Sebastian Prost, Clara Crivellaro, Andy Haddon, and Rob Comber. 2018. Food Democracy in the Making: Designing with Local Food Networks. In Proceedings of the 2018 CHI Conference on Human Factors in Computing Systems (CHI '18). ACM, New York, NY, USA, 333:1-333:14. https://doi.org/10.1145/3173574.3173907 event-place: Montreal QC, Canada.

[71] Barath Raghavan, Bonnie A. Nardi, Sarah Taylor Lovell, Juliet Norton, Bill Tomlinson, and Donald J. Patterson. 2016. Computational Agroecology: Sustainable Food Ecosystem Design. In Proceedings of the 2016 CHI Conference Extended Abstracts on Human Factors in Computing Systems (CHI EA '16). ACM, New York, NY, USA, 423-435. https: //doi.org/10.1145/2851581.2892577

[72] Ankita Raturi, Juliet Norton, Bill Tomlinson, Eli Blevis, and Lynn Dombrowski. 2017. Designing Sustainable Food Systems. (2017). www.foodchi.org

[73] Christian Remy and Elaine M. Huang. 2015. Limits and sustainable interaction design: Obsolescence in a future of collapse and resource scarcity. First Monday 20, 8 (July 2015). https://doi.org/10.5210/fm.v20i8.6122

[74] Brett H. Robinson. 2009. E-waste: An assessment of global production and environmental impacts. Science of The Total Environment 408, 2 (Dec. 2009), 183-191. https://doi.org/10.1016/j.scitotenv.2009.09.044

[75] Larry D. Rosen, Mark L. Carrier, and Nancy A. Cheever. 2013. Facebook and texting made me do it: Media-induced task-switching while studying. Computers in Human Behavior 29, 3 (May 2013), 948-958. https://doi.org/10.1016/j.chb. 2012.12.001

[76] Mizuki Sakamoto and Tatsuo Nakajima. 2013. Micro-crowdfunding: achieving a sustainable society through economic and social incentives in micro-level crowdfunding. ACM Press, 1-10. https://doi.org/10.1145/2541831.2541838

[77] Johnny Saldaña. 2013. The coding manual for qualitative researchers (2nd ed ed.). SAGE, Los Angeles. OCLC: ocn796279115.

[78] Liselotte Schebek, Witold-Roger Poganietz, Silke Feifel, and Saskia Ziemann. 2015. Technological Innovation and Anthropogenic Material Flows. In Competition and Conflicts on Resource Use, Susanne Hartard and Wolfgang Liebert (Eds.). Springer International Publishing, Cham, 135-153. https://doi.org/10.1007/978-3-319-10954-1_10

[79] James C. Scott. 2014. Two Cheers for Anarchism: Six Easy Pieces on Autonomy, Dignity, and Meaningful Work and Play (new in paper edition ed.). Princeton University Press, Princeton, NJ Oxford.

[80] Geraint Rhys Sethu-Jones, Yvonne Rogers, and Nicolai Marquardt. 2017. Data in the Garden: A Framework for Exploring Provocative Prototypes As Part of Research in the Wild. In Proceedings of the 29th Australian Conference on Computer-Human Interaction (OZCHI '17). ACM, New York, NY, USA, 318-327. https://doi.org/10.1145/3152771.3152805

[81] M. Six Silberman. 2015. Information systems for the age of consequences. First Monday 20, 8 (July 2015). https: //doi.org/10.5210/fm.v20i8.6128

[82] Rosemary Steup, Arvind Santhanam, Marisa Logan, Lynn Dombrowski, and Norman Makoto Su. 2018. Growing Tiny Publics: Small Farmers' Social Movement Strategies. Proc. ACM Hum.-Comput. Interact. 2, CSCW (Nov. 2018), 165:1-165:24. https://doi.org/10.1145/3274434

[83] Joseph A. Tainter. 1988. The collapse of complex societies. Cambridge University Press, Cambridge, Cambridgeshire ; New York.

[84] Joseph A. Tainter. 2006. Social complexity and sustainability. Ecological Complexity 3, 2 (June 2006), 91-103. https: //doi.org/10.1016/j.ecocom.2005.07.004

[85] Joshua Tanenbaum, Marcel Pufal, and Karen Tanenbaum. 2016. The Limits of Our Imagination: Design Fiction As a Strategy for Engaging with Dystopian Futures. In Proceedings of the Second Workshop on Computing Within Limits (LIMITS '16). ACM, New York, NY, USA, 10:1-10:9. https://doi.org/10.1145/2926676.2926687

[86] Bill Tomlinson, Eli Blevis, Bonnie Nardi, Donald J. Patterson, M. SIX Silberman, and Yue Pan. 2013. Collapse Informatics and Practice: Theory, Method, and Design. ACM Trans. Comput.-Hum. Interact. 20, 4 (Sept. 2013), 24:1-24:26. https: //doi.org/10.1145/2493431

[87] Bill Tomlinson, Bonnie A. Nardi, Donald J. Patterson, Ankita Raturi, Debra Richardson, Jean-Daniel Saphores, and Dan Stokols. 2015. Toward Alternative Decentralized Infrastructures. ACM Press, 33-40. https://doi.org/10.1145/2830629. 2830648 
[88] Bill Tomlinson, Juliet Norton, Eric P. S. Baumer, Marcel Pufal, and Barath Raghavan. 2015. Self-Obviating Systems and their Application to Sustainability. (March 2015). https://www.ideals.illinois.edu/handle/2142/73442

[89] Bill Tomlinson, Donald J. Patterson, Yue Pan, Eli Blevis, Bonnie A. Nardi, Six Silberman, Juliet Norton, and Joseph J. LaViola. 2012. What if sustainability doesn't work out? interactions 19, 6 (Nov. 2012), 50. https://doi.org/10.1145/ 2377783.2377794

[90] Anita Marie Tsaasan and Bonnie A. Nardi. 2018. Think local act local. In Digital Technology and Sustainability. Routledge, 217-230. https://doi.org/10.9774/GLEAF.9781315465975_25

[91] Hayley Tsukayama. 2017. Mark Zuckerberg tells Harvard grads that automation will take jobs, and it's up to millennials to create more. Washington Post (May 2017). https://www.washingtonpost.com/news/the-switch/wp/2017/05/25/ mark-zuckerberg-tells-harvard-grads-that-automation-will-take-jobs-and-its-up-to-millennials-to-create-more/

[92] João H. Costa Vargas. 2008. Activist Scholarship: Limits and Possibilities in Times of Black Genocide. In Engaging Contradictions (1 ed.), CHARLES R. HALE (Ed.). University of California Press, 164-182. http://www.jstor.org/stable/ 10.1525/j.ctt1pncnt.12

[93] Xiaolan Wang, Ron Wakkary, Carman Neustaedter, and Audrey Desjardins. 2015. Information Sharing, Scheduling, and Awareness in Community Gardening Collaboration. In Proceedings of the 7th International Conference on Communities and Technologies. ACM, New York, NY, USA, 79-88. https://doi.org/10.1145/2768545.2768556

[94] Agung Toto Wibowo, Advaith Siddharthan, Helen Anderson, Annie Robinson, Nirwan Sharma, Helen Bostock, Andrew Salisbury, Richard Comont, and René van der Wal. 2017. Bumblebee Friendly Planting Recommendations with Citizen Science Data. In Proceedings of the International Workshop on Recommender Systems for Citizens (CitRec '17). ACM, New York, NY, USA, 4:1-4:6. https://doi.org/10.1145/3127325.3128330

[95] Langdon Winner. 1977. Autonomous technology: technics-out-of-control as a theme in political thought. MIT Press, Cambridge, Mass.

[96] Daisy Yoo, Katie Derthick, Shaghayegh Ghassemian, Jean Hakizimana, Brian Gill, and Batya Friedman. 2016. Multilifespan Design Thinking: Two Methods and a Case Study with the Rwandan Diaspora. In Proceedings of the 2016 CHI Conference on Human Factors in Computing Systems (CHI '16). ACM, New York, NY, USA, 4423-4434. https: //doi.org/10.1145/2858036.2858366 event-place: San Jose, California, USA.

Received April 2019; revised June 2019; accepted August 2019 